\title{
Outcome of Involuntary Medication in a State Hospital System
}

\author{
Francine Cournos, M.D., Karen McKinnon, M.A., and Barbara Stanley, Ph.D.
}

\begin{abstract}
Objective: The purpose of the study was to examine the course of involuntarily administered medication in a state hospital population. Method: The authors retrospectively examined the records of all 51 involuntarily medicated patients in six state hospitals in New York City in a single calendar year. Clinical course was recorded for the period of involuntary medication and for 12 months thereafter. These patients were compared to 51 patients on the same wards who accepted medication. Results: Clinicians assessed involuntarily medicated patients as more dangerous to themselves or others and less delusional after treatment than the comparison patients. Long-acting intramuscular antipsychotics were prescribed more frequently for involuntarily medicated patients. No differences were observed in rates of discharge, outpatient cooperation, or rehospitalization. Half of the patients in both groups remained continuously institutionalized, and of those who left the hospital, only $30 \%$ of the involuntarily medicated group and $40 \%$ of the comparison group took medication as outpatients. Conclusions: For these chronically severely ill patients, involuntary medication did not appear to enhance insight or cooperation or result in rapid return to the community. Involuntary medication is often a necessary short-term, in-hospital management strategy, but it does not replace the need to develop comprehensive, long-term inpatient and community-based approaches to the management of treatment refusal.
\end{abstract}

(Am J Psychiatry 1991; 148:489-494)

A lthough the right of committed patients to refuse medication has now been asserted for a decade (1), we know little about what happens after a course of involuntary treatment (2). The rationale for involuntary medication is that it is in the best interest of the patient, will improve the patient's contact with reality and diminish dangerousness to self and others, will help the patient acknowledge the need for continued treatment, and will ultimately yield better treatment compliance. Most studies of involuntary medication focus on patients' reasons for refusing medication. Refusal may be based on the patient's illness, such as psychotic ideas about medication or denial of illness (2-7); legitimate complaints about the treatment itself, including severe side effects or lack of efficacy $(3,8)$; or the patient's personality, such as the desire to maintain control $(2,5)$. However, studies have not examined

Received April 16, 1990; revision received Sept. 5, 1990; accepted Sept. 25, 1990. From New York State Psychiatric Institute. Address reprint requests to Dr. Cournos, New York State Psychiatric Institute, 722 West 168th St., New York, NY 10032.

Supported in part by NIMH grants MH-41734 and MH-41735 to Dr. Stanley.

The authors thank Jeannine R. Guido, Cathie M. Currie, and Paul S. Appelbaum, M.D., for their assistance.

Copyright (C) 1991 American Psychiatric Association. whether our assumptions about the long-term effects of involuntary medication are valid.

While involuntarily medicated patients may later express positive feelings about their treatment $(6,9)$, the frequency with which such patients continue to take medication after discharge is not known. Previous outcome studies have been rare and long-term follow-up has been neglected. In a small-scale study involving 10 state hospital patients, patients who refused medication remained hospitalized longer and were rehospitalized sooner than those who consented (5). Medication compliance after discharge did not appear to differ from that of matched control subjects.

Most of the landmark legal decisions about involuntary treatment grew out of cases in state hospitals $(1,10)$. For this reason it is important to study the outcome of involuntary medication among patients in this setting.

This retrospective study examined the inpatient and outpatient histories of a group of state hospital patients who had completed a course of involuntary medication and compared their outcomes to those of a group of matched patients who complied with medication in the hospital. We sought to determine whether involuntarily medicated patients would be 1 ) less likely to leave the hospital within the study period or have 
TABLE 1. Demographic and Clinical Characteristics of Involuntarily Medicated and Comparison Patients

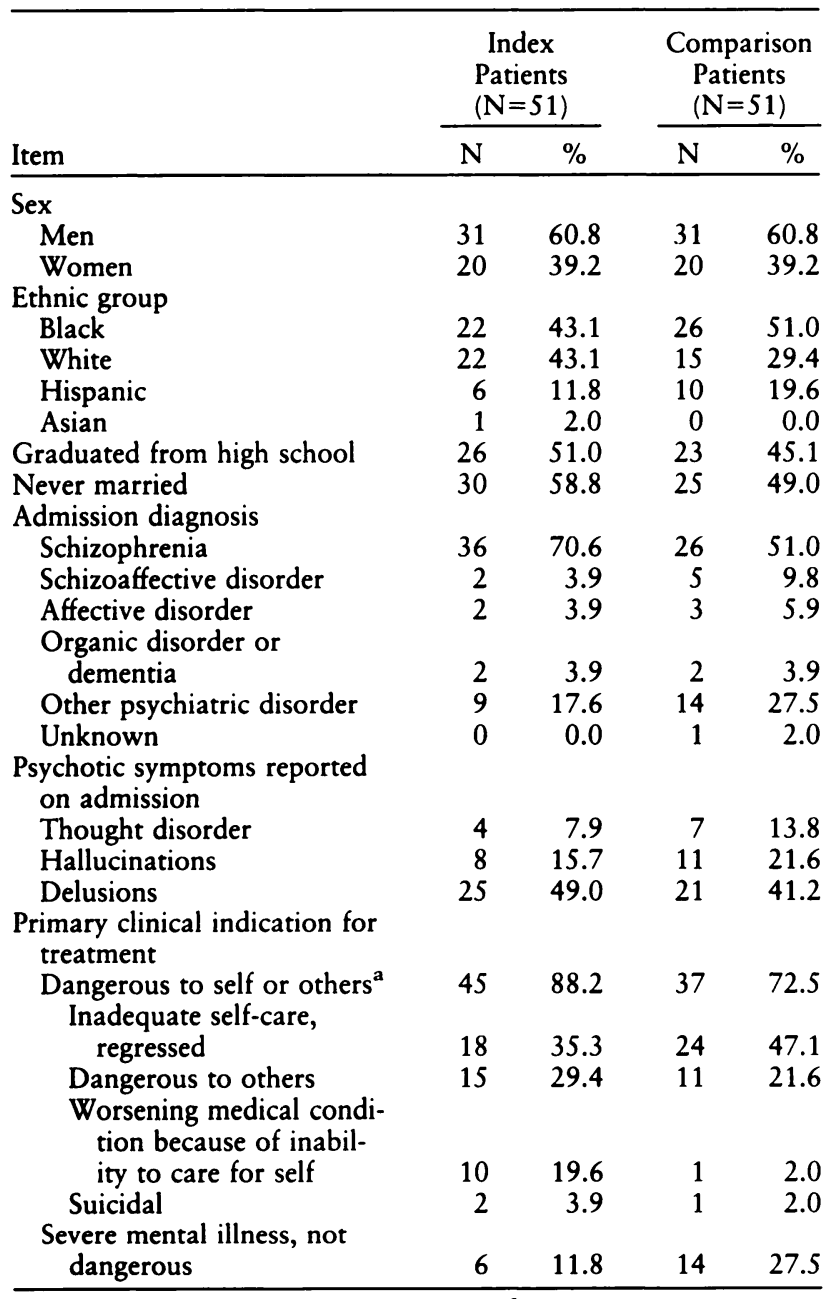

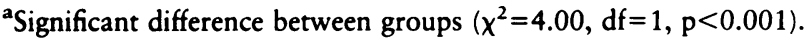

significantly longer lengths of stay in the hospital, 2) more likely to refuse other inpatient care such as food, personal hygiene, and medical treatment in addition to psychiatric medication, 3) less likely to comply with outpatient treatment after discharge, and 4) more likely to be rehospitalized during the follow-up period.

\section{METHOD}

We examined the treatment histories of patients involuntarily hospitalized and medicated in the six state hospitals for adults in New York City, comprising approximately 4,300 beds. Inpatient and outpatient records of all 51 patients who received administiative approval for involuntary medication during the 12 month period from Jan. 1 to Dec. 31, 1985, were reviewed. Fifty-one patients matched for hospital ward and legal status at the time of the index patients' first clinical evaluation for involuntary medication were selected as a comparison group. Ward was selected as a matching variable in order to control for effects of staff attitudes toward the use of involuntary medication. Legal status was selected to control for severity of illness, since the literature indicates that involuntary patients may be more severely ill than voluntary patients (11-13). Records from admission through the 12 months after termination of the index patients' involuntary treatment approval period were reviewed for both patient groups. At the time of the first evaluation for involuntary medication, $40(78.4 \%)$ of the index patients had civil commitment status, six $(11.8 \%)$ had criminal commitment status, and five $(9.8 \%)$ were voluntary. Matched patients had identical legal status at the time of the first evaluation. However, the few voluntary index patients were converted to involuntary status, as required by New York State regulations, before the final involuntary medication approval was given.

Legal status on admission was only slightly different in the two groups. Thirty-seven $(72.5 \%)$ involuntarily medicated patients had civil commitment status, and $10(19.6 \%)$ had criminal commitment status; only four $(7.8 \%)$ were voluntarily admitted. Among the comparison group, $35(68.6 \%)$ had civil commitment status, six $(11.8 \%)$ had criminal status, and seven $(13.7 \%)$ were voluntarily admitted. Three $(5.9 \%)$ of the matched patients had unknown legal status on admission. Thus, to the extent that involuntary admission correlates with greater severity of illness, the two patient groups were not significantly different on admission.

Data were collected by reviewing all documents generated by the involuntary treatment procedure, including clinical evaluations and final outcome reports, and patients' charts. For the comparison group, all data were obtained from patients' charts. In-hospital medication compliance was measured by reviewing nursing records, which documented the medications ordered and the frequency with which patients accepted them. Outpatient compliance was determined by review of outpatient charts. All inpatient data were derived from New York State hospital records. Chart reviews were supplemented with data from the State Office of Mental Health's computerized patient information system.

The fourth and final judgment regarding involuntary medication for all state hospital patients in New York City in 1985 was made by a physician under the clinical administrative review procedure used at that time in New York State. The review procedure and subsequent changes have been described elsewhere (14).

\section{RESULTS}

Fifty-two applications for involuntary medication were made during 1985 . This represents $0.37 \%$ of the total number of patients in treatment in New York City's adult state hospitals during the 1-year period. One patient's objection to involuntary medication was 


\begin{tabular}{|c|c|c|c|c|c|c|c|c|c|}
\hline \multirow[b]{2}{*}{ Item } & \multicolumn{2}{|c|}{$\begin{array}{c}\text { Total } \\
(\mathrm{N}=102)\end{array}$} & \multicolumn{2}{|c|}{$\begin{array}{c}\text { Index } \\
\text { Patients } \\
(\mathrm{N}=51) \\
\end{array}$} & \multicolumn{2}{|c|}{$\begin{array}{c}\text { Comparison } \\
\text { Patients } \\
(\mathrm{N}=51) \\
\end{array}$} & \multicolumn{3}{|c|}{$\begin{array}{l}\text { Chi-Square } \\
\text { Analysis } \\
\end{array}$} \\
\hline & $\mathrm{N}$ & $\%$ & $\mathrm{~N}$ & $\%$ & $\mathbf{N}$ & $\%$ & $x^{2}$ & df & $\mathrm{p}$ \\
\hline Inpatient antipsychotic medications $(\mathrm{N}=68)$ & & & & & & & 17.18 & 1 & $<0.0001$ \\
\hline Intramuscular depot antipsychotic & 28 & 27.5 & 24 & 47.1 & 4 & 7.9 & & & \\
\hline Oral antipsychotic & 40 & 39.2 & 14 & 27.5 & 26 & 51.0 & & & \\
\hline \multicolumn{10}{|l|}{ Inpatient medication noncompliance } \\
\hline $\begin{array}{l}3 \text { months before index patient's involuntary } \\
\text { medication }(\mathrm{N}=92)\end{array}$ & & & & & & & 35.12 & 2 & $<0.0001$ \\
\hline$>90 \%$ & 24 & 23.5 & 23 & 45.1 & 1 & 2.0 & & & \\
\hline Intermittent & 15 & 14.7 & 11 & 21.6 & 4 & 7.8 & & & \\
\hline$<10 \%$ & 53 & 52.0 & 14 & 27.5 & 39 & 76.5 & & & \\
\hline Period for which index patient's involuntary & & & & & & & & & \\
\hline $\begin{array}{l}\text { treatment was approved }(\mathrm{N}=87) \\
>90 \%\end{array}$ & & & & & & & $18.00^{\mathrm{a}}$ & 2 & 0.0001 \\
\hline$>90 \%$ & 8 & 7.8 & 7 & 13.7 & 1 & 2.0 & & & \\
\hline Intermittent & 19 & 18.6 & 17 & 33.3 & 2 & 3.9 & & & \\
\hline$<10 \%$ & 60 & 58.8 & 24 & 47.1 & 36 & 70.6 & & & \\
\hline \multirow{2}{*}{\multicolumn{10}{|c|}{$\begin{array}{l}\text { Hospitalization within the } 12 \text { months after end } \\
\text { of index patient's treatment approval period } \\
(N=76)\end{array}$}} \\
\hline & & & & & & & $14.29^{\mathrm{a}}$ & 2 & 0.0008 \\
\hline$>90 \%$ & 7 & 6.9 & 7 & 13.7 & 0 & 0.0 & & & \\
\hline Intermittent & 12 & 11.8 & 10 & 19.6 & 2 & 3.9 & & & \\
\hline$<10 \%$ & 57 & 55.9 & 23 & 45.1 & 34 & 66.7 & & & \\
\hline \multicolumn{10}{|l|}{ Noncompliance with other inpatient care } \\
\hline Refused bathing/other self-care $(\mathrm{N}=101)$ & 37 & 36.3 & 19 & 37.3 & 18 & 35.3 & 0.02 & 1 & 0.90 \\
\hline Refused to eat $(\mathrm{N}=101)$ & 24 & 23.5 & 16 & 31.4 & 8 & 15.7 & 3.29 & 1 & 0.07 \\
\hline Refused medical evaluation/treatment $(\mathrm{N}=100)$ & 47 & 46.1 & 30 & 58.8 & 17 & 33.3 & 5.84 & 1 & 0.02 \\
\hline \\
\hline$(\mathrm{N}=32)$ & & & & & & & $2.34^{\mathrm{a}}$ & 1 & 0.13 \\
\hline Intramuscular depot antipsychotic & 17 & 16.7 & 16 & 31.4 & 1 & 2.0 & & & \\
\hline Oral antipsychotic & 15 & 14.7 & 10 & 19.6 & 5 & 9.8 & & & \\
\hline
\end{tabular}

'Yates' correction for continuity.

upheld. Thus, 51 patients (98\%) received administrative approval for involuntary medication. Thirty $(58.8 \%)$ patients received approval for 3 months, nine $(17.6 \%)$ for 6 months, five $(9.8 \%)$ for 9 months, four $(7.8 \%)$ for 12 months, and three $(5.9 \%)$ for more than 1 year.

The 51 matched patients were compared with the 51 patients who were involuntarily medicated. The patient groups were not significantly different on any demographic variable. The mean $\pm \mathrm{SD}$ ages of the index and comparison groups were $46.5 \pm 15.7$ and $44.5 \pm$ 16.0 years. Furthermore, the clinical profiles of the index and comparison groups were similar in terms of known admission diagnosis, psychotic symptoms, and number of previous total $(5.0 \pm 4.7$ versus $5.1 \pm 5.1)$ and involuntary $(2.0 \pm 2.1$ versus $2.5 \pm 4.6)$ psychiatric hospitalizations. However, involuntarily medicated patients were more frequently reported by clinicians as being dangerous to themselves or others than were the matched patients (table 1).

Not surprisingly, despite similar diagnoses, the patient groups differed significantly in the frequency with which they were given depot intramuscular versus oral antipsychotic medication (table 2 ).

Although intermittent medication refusal was observed in both groups, persistent refusal, as expected, was significantly more common among the involuntarily medicated group than the comparison group.
Persistent refusal was defined as a rate of more than $90 \%$ noncompliance with prescribed medications in a given period.

Although differences on other measures of compliance failed to reach significance, there appeared to be a tendency among patients who refused medication to be more reluctant to accept other forms of patient care, particularly food. No differences were observed in the number of occasions of restraint or seclusion.

Of the four involuntarily medicated patients with documented thought disorder on admission, two showed improvement in that symptom at the end of the involuntary medication period. Of the seven matched patients with documented thought disorder, two were reported improved. Of the eight involuntarily medicated patients with documented hallucinations, five had improvement in that symptom, while five of the 11 matched patients with documented hallucinations on admission were reported improved. These differences were not statistically significant. Of the 25 involuntarily medicated patients with documented delusions on admission, $15(60.0 \%)$ were less delusional, while only five $(23.8 \%)$ of the 21 matched patients with documented delusions on admission were reported improved. This difference was statistically significant $\left(\chi^{2}=6.09, \mathrm{df}=1, \mathrm{p}<0.02\right)$. This difference was not explained by intramuscular versus oral antipsychotic medication. 
TABLE 3. 12-Month Outcome of Involuntarily Medicated and Comparison Patients

\begin{tabular}{|c|c|c|c|c|c|c|c|c|}
\hline \multirow[b]{3}{*}{ Outcome } & \multicolumn{4}{|c|}{ All Subjects } & \multicolumn{4}{|c|}{ Rehospitalized Subjects } \\
\hline & \multicolumn{2}{|c|}{$\begin{array}{c}\text { Index } \\
(\mathrm{N}=51)\end{array}$} & \multicolumn{2}{|c|}{$\begin{array}{c}\text { Comparison } \\
(\mathrm{N}=51)\end{array}$} & \multicolumn{2}{|c|}{$\begin{array}{l}\text { Index } \\
(\mathrm{N}=7)\end{array}$} & \multicolumn{2}{|c|}{$\begin{array}{c}\text { Comparison } \\
(\mathrm{N}=8)\end{array}$} \\
\hline & $\mathrm{N}$ & $\%$ & $\mathrm{~N}$ & $\%$ & $\mathrm{~N}$ & $\%$ & $\mathbf{N}$ & $\%$ \\
\hline Continuously institutionalized & 24 & 47.1 & 27 & 52.9 & & & & \\
\hline Hospital & 21 & 41.2 & 23 & 45.1 & & & & \\
\hline Nursing home & 3 & 5.9 & 4 & 7.9 & & & & \\
\hline \multicolumn{9}{|l|}{ Died because of medical illness while } \\
\hline inpatient & 2 & 3.9 & 0 & 0.0 & 0 & 0.0 & 0 & 0.0 \\
\hline Discharged, follow-up available & 23 & 45.1 & 20 & 39.2 & 6 & 85.7 & 8 & 100.0 \\
\hline Eloped without outpatient plan & 4 & 7.8 & 5 & 9.8 & 1 & 14.3 & 1 & 12.5 \\
\hline Refused outpatient referral & 4 & 7.8 & 1 & 2.0 & 2 & 28.6 & 0 & 0.0 \\
\hline \multicolumn{9}{|l|}{ Refused outpatient referral, died by } \\
\hline suicide & 1 & 2.0 & 0 & 0.0 & 0 & 0.0 & 0 & 0.0 \\
\hline Never attended clinic & 4 & 7.8 & 4 & 7.8 & 1 & 14.3 & 2 & 25.0 \\
\hline 1 or 2 clinic visits only & 2 & 3.9 & 2 & 3.9 & 1 & 14.3 & 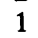 & 12.5 \\
\hline Complied with visits but not medication & 1 & 2.0 & 0 & 0.0 & 0 & 0.0 & 0 & 0.0 \\
\hline Complied with visits and medication & 7 & 13.7 & 8 & 15.7 & 1 & 14.3 & 4 & 50.0 \\
\hline Discharged, no follow-up & 2 & 3.9 & 4 & 7.8 & 1 & 14.3 & 0 & 0.0 \\
\hline & 1 & 2.0 & 4 & 7.8 & 1 & 14.3 & 0 & 0.0 \\
\hline \multicolumn{9}{|l|}{ No outpatient medication prescribed; } \\
\hline treatment & 1 & 2.0 & 0 & 0.0 & 0 & 0.0 & 0 & 0.0 \\
\hline
\end{tabular}

The median length of stay for the overall hospital population was 52 days. The involuntary groups we examined had considerably longer stays. Involuntarily medicated patients had a mean \pm SD hospital stay of $35.7 \pm 43.1$ months. Matched patients had a mean stay of $66.5 \pm 123.8$ months. Although there was a large between-group difference, it was not statistically significant because of the large standard deviations.

Table 3 summarizes rates of attendance at outpatient facilities after discharge, medication compliance, and rehospitalization for both patient groups. There were no significant differences in postdischarge outcome between those who were involuntarily medicated and those who accepted medication voluntarily.

After 12 months, approximately one-half $(\mathrm{N}=24$, $47.1 \%$ ) of the involuntarily medicated patients remained institutionalized. When the two patients for whom follow-up was not relevant or available (one was not prescribed medication, one had no available records) were excluded, only seven $(30.4 \%)$ of the 23 involuntarily medicated patients who left the hospital complied with clinic visits and accepted medication. After 12 months, $27(52.9 \%)$ of the matched patients were still institutionalized. Of 20 who left the hospital and for whom follow-up was available, only eight $(40 \%)$ complied with clinic visits and medication.

Rehospitalization rates were derived from the New York State hospital inpatient database and records. Non-state-hospital records could not be obtained. One involuntarily medicated patient was rehospitalized after 9.7 months despite compliance with outpatient medication. Four outpatient, medication-compliant matched patients were rehospitalized after a mean of $11.9 \pm 4.6$ months. These rates were not statistically significant.

\section{DISCUSSION}

The large state hospital system in New York City appears to reserve the use of involuntary medication for the patients who most persistently refuse medication and who are also considered dangerous to themselves or others. Although the median length of stay for all state hospital patients was 52 days, the average patient approved for involuntary medication had already been in the hospital for 17.5 months. Comparison patients also had long stays because they were selected from the same wards as the patients who had refused medication, and, generally speaking, these were units designated for long-term care rather than for newly admitted patients. Patients for whom formal petitions for involuntary medication were made may have exhausted most other treatment options.

This study, then, compared two groups of long-stay involuntary patients: those who refused both hospitalization and medication and those who refused hospitalization but, once institutionalized, complied with medication. Involuntarily medicated patients were reported to be significantly less delusional than matched patients at the end of the involuntary treatment period. This difference was not explained by greater use of depot medications. This benefit must be interpreted with caution. The difference in improvement rates may be biased, since extensions of involuntary medication were granted on the basis of clinicians' progress reports. Furthermore, while delusions were reportedly ameliorated after a course of involuntary medication, improvement had no impact on long-term outcome.

A course of involuntary medication did not appear to have either a negative or a positive effect on longterm outcome. We did not find significant differences in hospital course or outpatient compliance between 
the two patient groups. Whether or not they complied with in-hospital medication, $60 \%-70 \%$ of patients were resistant to continuing treatment after discharge.

This study could have underestimated treatment compliance, since patients who left the hospital without consent and never reentered the state system may have sought treatment elsewhere. However, it is more likely that the number of patients discontinuing treatment is an underestimate, since outpatient medication compliance records were based on patient self-reports. Our results are consistent with previous findings of a long-term unwillingness among committed patients to engage in follow-up services (12). Patients' resistance was also reflected in refusal of food, self-care of personal hygiene, and medical treatment while in the hospital, which occurred among patients who accepted psychotropic medication as well as those who rejected it.

Involuntarily medicated patients were more likely to persistently refuse medication as inpatients and to receive treatment with long-acting, intramuscular antipsychotic drugs. Psychiatrists appear to prescribe longacting antipsychotics to avoid continuous confrontation between the patient and the nursing staff or to ensure that the patient does not evade the medication in pill form. This desire to be certain that patients receive medication may follow from the apparently dire status of the illness presented to clinicians; $88.2 \%$ of involuntarily medicated patients were dangerous to themselves or others. This is consistent with the evidence that of patients who refuse medication, those who reach the formal review process are more severely ill than are those who can eventually be persuaded by clinicians to accept medication and those discharged without receiving a course of medication (15).

With the severely ill population studied, involuntary medication appeared to be a necessary management tool for in-hospital care (14); but for most, it did not result in rapid return to the community or later compliance with medication. For many long-stay chronic patients, a course of involuntary medication in the hospital appears to be a short-term strategy that does not produce the insight and cooperation that psychiatrists hope to achieve.

Although some investigators have found that committed patients later accept voluntary hospitalization $(16,17)$ and that involuntarily medicated patients later express agreement with the need for treatment (9), those studies were performed in general hospital settings with less chronic patients and did not examine medication compliance. Our study was conducted in state hospitals with a chronic mentally ill population. Among the chronic mentally ill, treatment refusal may be associated with severe illness incompatible with rapid discharge, and even when discharge is possible, may be associated with persistent refusal despite improvement with medication. The patients we studied had numerous previous psychiatric hospitalizations, many of which were involuntary. Medication refusal may reflect a well-entrenched pattern of resistance to treatment. In that case the results of this study suggest that it may be counterproductive to wait to intervene only when refusal is persistent and the patient is chronically ill and that earlier intervention may be more successful. Alternatively, these patients may have a more severe form of illness (15) that might affect their appreciation of the need for treatment even if there is symptom improvement with medication.

Our findings suggest that it may be important to consider alternatives for the long-term management of patients who refuse treatment. When treatment refusal has become a chronic pattern, those in need of continued care could be considered for an expanded use of outpatient commitment (18-20). However, not all patients who refuse treatment are appropriate for aggressive intervention in or out of the hospital, either because they are competent to reject care or can function adequately, if not optimally, even without treatment or because the treatment does not produce sufficiently beneficial therapeutic results. For these patients we need to consider more successful strategies of engagement including provision of sanctuary without treatment in the community. Sanctuary could provide shelter and food while clinicians work to encourage patients to accept mental health services.

While we obtained 12-month follow-up data on 50 $(98 \%)$ of 51 patients who had completed a course of involuntary medication in a state hospital and on 47 $(92 \%)$ of 51 matched comparison subjects, this study was retrospective in nature and thus limited in terms of the factors that could be explored and the ability to make causal inferences. We examined only committed patients whose stays were far longer than the typical state hospital patient's. In addition, we did not examine routine refusals that were allowed by staff; our system reserves involuntary medication for chronic, persistent refusal within a population so severely and chronically ill that they may be least likely to respond to the intervention. We urge the prospective examination in both inpatient and outpatient settings of the issues we have described here in order to develop better models for addressing medication refusal among severely mentally ill patients.

\section{REFERENCES}

1. Appelbaum PS: The right to refuse treatment with antipsychotic medications: retrospect and prospect. Am J Psychiatry 1988; 145:413-419

2. Appelbaum PS, Hoge SK: The right to refuse treatment: what the research reveals, in The Right to Refuse Treatment. Edited by Parry J. Washington, DC, American Bar Association, 1986

3. Van Putten T, Crumpton E, Yale C: Drug refusal in schizophrenia and the wish to be crazy. Arch Gen Psychiatry 1976; 33: 1443-1446

4. Marder SR, Mebane A, Chien CP, et al: A comparison of patients who refuse and consent to neuroleptic treatment. Am J Psychiatry 1983; 140:470-472

5. Hassenfeld IN, Grumet B: A study of the right to refuse treatment. Bull Acad Psychiatry Law 1984; 12:65-74

6. Marder SR, Swann E, Winslade WJ, et al: A study of medication refusal by involuntary psychiatric patients. Hosp Community 
Psychiatry $1984 ; 35: 724-726$

7. Zito JM, Routt WW, Mitchell JE, et al: Clinical characteristics of hospitalized psychotic patients who refuse antipsychotic drug therapy. Am J Psychiatry 1985; 142:822-826

8. Van Putten T: Why do schizophrenic patients refuse to take their drugs? Arch Gen Psychiatry 1974; 31:67-72

9. Schwartz HI, Vingiano W, Bezirganian C: Autonomy and the right to refuse treatment: patients' attitudes after involuntary medication. Hosp Community Psychiatry 1988; 39:1049-1054

10. Brooks AD: The right to refuse antipsychotic medications: law and policy. Rutgers Law Rev 1987; 39:339-376

11. Gove WR, Fain T: A comparison of voluntary and committed psychiatric patients. Arch Gen Psychiatry 1977; 34:669-676

12. Szmukler GI, Bird AS, Button EJ: Compulsory admissions in a London borough, I: social and clinical features and a follow-up. Psychol Med 1981; 11:617-636

13. Nicholson RA: Correlates of commitment status in psychiatric patients. Psychol Bull 1986; 100:241-250

14. Cournos F, McKinnon K, Adams C: A comparison of clinical and judicial procedures for reviewing requests for involuntary medication in New York. Hosp Community Psychiatry 1988; 39:851-855

15. Hoge SK, Appelbaum PS, Lawlor T, et al: A prospective, multicenter study of patients' refusal of antipsychotic medication. Arch Gen Psychiatry 1990; 47:949-962

16. Kane JM, Quitkin F, Rifkin A, et al: Attitudinal changes of involuntarily committed patients following treatment. Arch Gen Psychiatry 1983; 40:374-377

17. Tomelleri CJ, Lakshminarayanan N, Herjanic $M$ : Who are the “committed"? J Nerv Ment Dis 1977; 165:288-293

18. Scheid-Cook TL: Commitment of the mentally ill to outpatient treatment. Community Ment Health J 1987; 23:173-182

19. Wilk RJ: Implications of involuntary outpatient commitment for community mental health agencies. Am J Orthopsychiatry 1988; 58:580-591

20. Hiday VA, Scheid-Cook TL: A follow-up of chronic patients committed to outpatient treatment. Hosp Community Psychiatry $1989 ; 40: 52-59$ 